\title{
Dysplasia of the atrioventricular valves associated with conduction system anomalies
}

\author{
LUCIANO DALIENTO, ANDREA NAVA, GIUSEPPE FASOLI, ALESSANDRO MAZZUCCO, \\ GAETANO THIENE
}

From the Departments of Cardiology, Cardiovascular Surgery, and Pathology, University of Padua Medical School, Padua, Italy

SUMMARY Clinical, vectorcardiographic, and echocardiographic data from two siblings with atrial septal defects and dysplasia of the mitral and tricuspid valves are reported. Vectorcardiograms showed that both siblings had abnormal ventricular activation with initial electrical forces directed posteriorly. One sibling died after surgery, and necropsy showed incomplete differentiation of the leaflets and tensor apparatus producing anomalies resembling "mitral arcade." Serial histological examination of the conducting tissue showed that the atrioventricular node was located on the left side of the atrial septum, that the central fibrous body and the membranous septum were hypoplastic, and that an accessory nodoventricular pathway originating in the compact node joined the left side of the ventricular septum. This accessory pathway was probably the cause of the unusual ventricular activation.

Dysplasia of the mitral and tricuspid valves together with hypoplasia of the central fibrous body and the presence of accessory pathways are probably part of a malformative complex caused by incomplete differentiation of both the cardiac atrioventricular valves and the junctional area.

The term "dysplasia of an atrioventricular valve" currently refers to congenital malformation of the tricuspid valve. In 1971 Becker and Edwards ${ }^{1}$ described tricuspid valvular dysplasia as a spectrum of anomalies including "focal or diffuse thickening of the valve leaflets, deficient development of chordae and papillary muscles, improper separation of valve components from the ventricular wall, and focal agenesis of valvular tissue." Similar congenital lesions of the leaflets and tensor apparatus have also been found in the mitral valve but have been reported using different terminology, such as "typical" congenital mitral stenosis" and "mitral arcade." 3 We believe that the term dysplasia might be applied to these lesions as well. Bilateral atrioventricular valve dysplasia has rarely been reported, since usually only one valve is affected leading to valvular incompetence or stenosis. ${ }^{4-9}$

We report the findings in two siblings, who each had an atrial septal defect and dysplasia of the

Requests for reprints to Dr G Thiene, Istituto Anatomia Patologia, Via Gabelli 61, 35100 Padova, Italy.

Accepted for publication 20 September 1983 atrioventricular valves together with important anomalies of the specialised atrioventricular junction.

\section{Patients and methods}

\section{CASE 1}

A 9 year old boy with poor exercise tolerance was referred to the heart surgery department of the University of Padua for closure of an atrial septal defect. Examination of the heart showed moderate cardiomegaly, a right ventricular impulse, fixed splitting of the second sound, a short grade $2 / 6$ systolic heart murmur at the apex and at the left sternal border, and a tricuspid diastolic rumble.

\section{Investigations}

The electrocardiogram showed sinus rhythm ( 80 beats $/ \mathrm{min}, \mathrm{AP}=0^{\circ}, \mathrm{AQRS}=+120^{\circ}, \mathrm{AT}=-30^{\circ}$, hypertrophy of the right atrium, incomplete right bundle branch block, and right axis deviation (Fig. 1). The vectorcardiogram showed a clockwise rotation in the horizontal and left sagittal planes, while the loop in the frontal plane showed a figure of eight configuration. The initial QRS forces (first $10 \mathrm{~ms}$ ) were directed towards the left, anteriorly, inferiorly, 

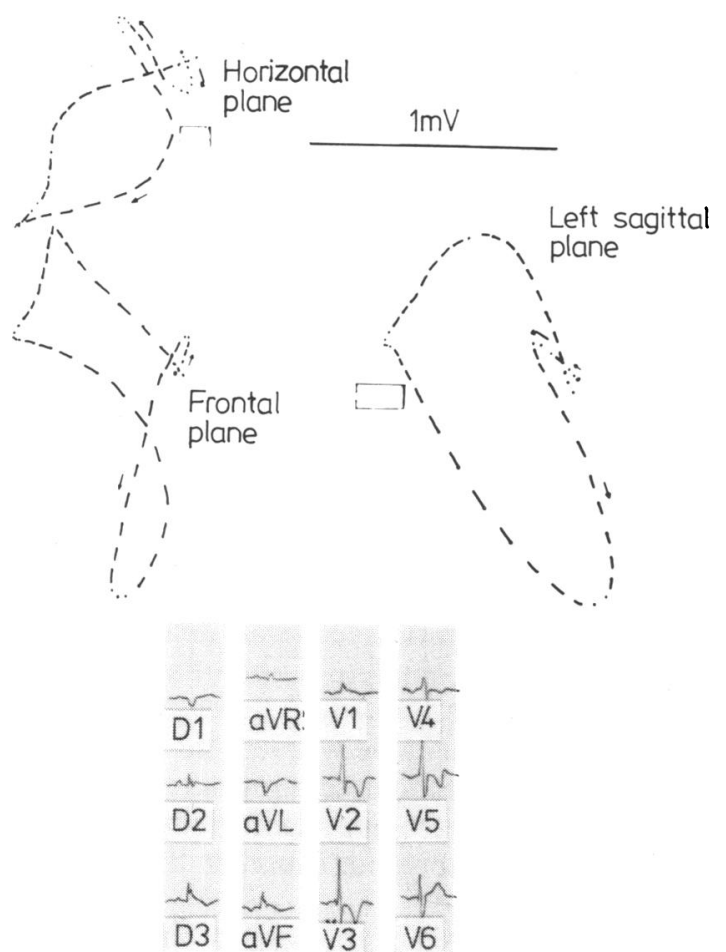

Fig. 1 Electrocardiogram and vectorcardiogram showing conduction anomalies in a 9 year old boy (case 1). Note the abnormal course of the loop: the initial QRS forces are directed towards the left, anteriorly and superiorly then suddenly change direction moving posteriorly, inferiorly, and slightly to the right. and superiorly, but they changed direction sharply, moving posteriorly, inferiorly, and slightly to the right (these forces lasted for about $30 \mathrm{~ms}$ ); finally the loop assumed the typical morphology of right bundle branch block (Fig. 1).

The phonocardiogram (Fig. 2a) confirmed a fixed splitting of the second heart sound, the presence of an apical systolic murmur, and a short mid-diastolic murmur at the apex and pulmonary area.

An $M$ mode echocardiogram showed an enlarged left atrium $(31 \mathrm{~mm})$, prominent dilatation of the right ventricle with paradoxical septal motion, large diastolic excursions of the tricuspid leaflets, and a slightly thickened anterior mitral leaflet (Fig. 2b).

Cardiac catheterisation, performed elsewhere, showed a large left to right atrial shunt and normal pressures in the pulmonary artery and both ventricles.

\section{Surgery}

Surgery was undertaken using the standard cardiopulmonary bypass procedure with mild hypothermia, aortic cross clamping, and cold potassium cardioplegia. At first inspection from the atrial side the mitral valve did not appear to be grossly malformed. The atrial septal defect was closed by the insertion of a large Dacron patch, but on reperfusion the heart was unable to sustain an acceptable output. A second period of cardiac ischaemia was, therefore, induced and the atrial septal patch removed. Detailed examination of the anatomy of the mitral valve showed muscularisation of the anterior leaflet, dysplasia of the posterior leaflet, and a leak at the posterior commis-

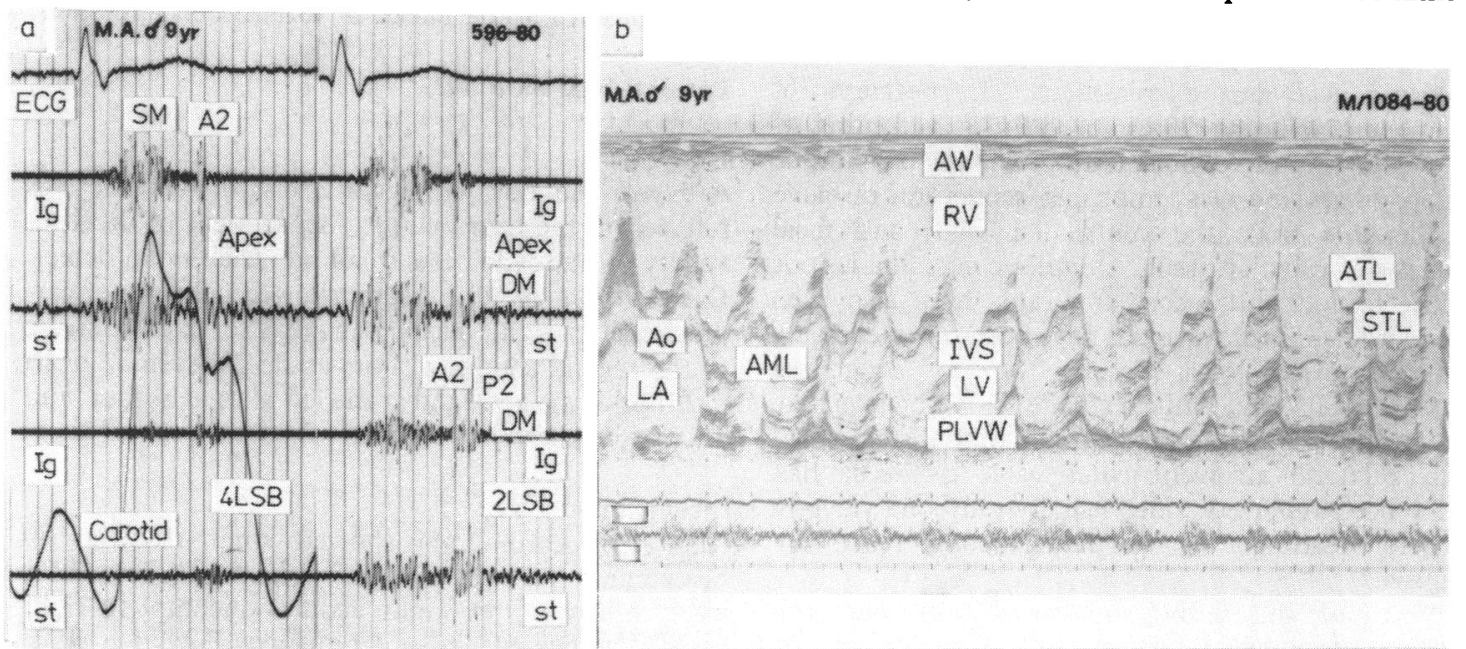

Fig. 2 (a) Phonocardiogram from case 1 showing the first sound of small amplitude, and the second with fixed splitting (about 40 $\mathrm{ms})$, with components being of equal amplitude; note the pansystolic regurgitant murmur $(S M)$ at the apex and the mid-diastolic murmur (DM) recorded at the apex and pulmonary area; and $(b) M$ mode echocardiogram showing an increased left atrial dimension, pronounced dilatation of the right ventricle $(R V)$ with reversed septal motion, and large diastolic excursions of the tricuspid leaflets $(A T L, S T L)$; the anterior mitral leaflet $(A M L)$, slightly thickened, is best seen at the level of the atrioventricular junction just beneath the aortic root $(A o)$, while the echoes from the posterior mitral leaflet merge with those of the posterior left ventricular wall $(P L V W)$. AW, anterior wall, IVS, interventricular septum; LA, left atrium, $L V$, left ventricle, $L S B$, left sternal border. 

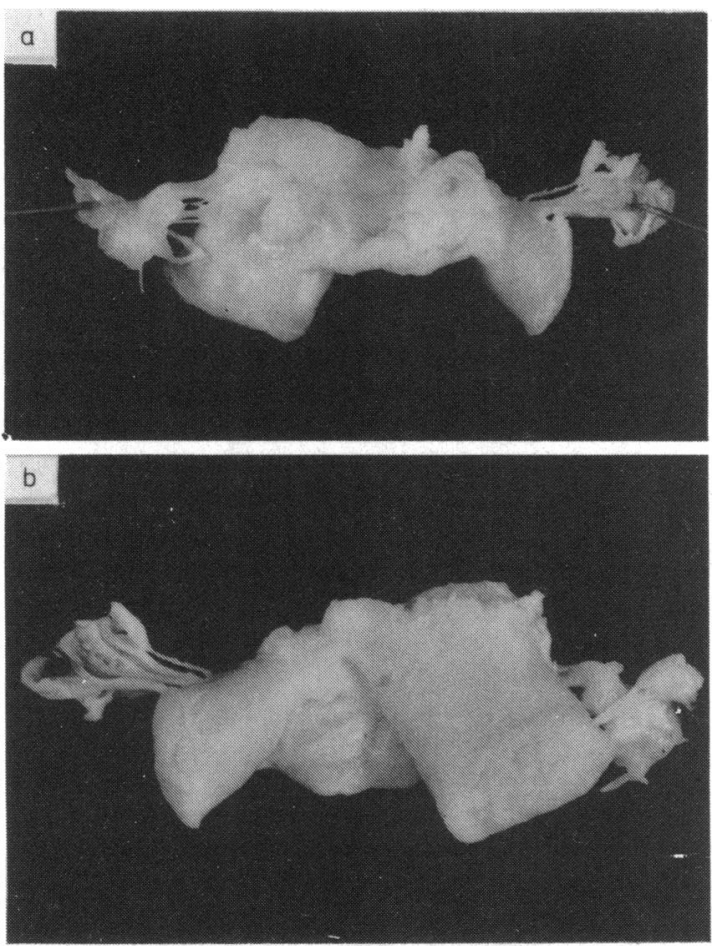

Fig. 3 Macroscopic view of the excised mitral valve showing (a) the atrial surface, and (b) the ventricular surface (case 1). Note the direct insertion of the papillary muscles into the valvular leaflets, the absence of chordae tendineae, and the mucoid aspect of the anterior leaflet.

sure. An annuloplasty was performed, but since no haemodynamic improvement was achieved the mitral valve was replaced with a Sorin tilting disc prosthesis. A De Vega type tricuspid annuloplasty was also performed. Despite these measures the heart did not regain sufficient contractility, and the patient could not be weaned off cardiopulmonary bypass.

\section{Pathological findings}

Examination of the excised mitral valve (Fig. 3) showed no chordae tendineae on the anterior leaflet, which appeared to be attached directly to the papillary muscle and formed a mitral arcade. The papillary muscles lacked a discrete apex and were attached to the ventricular surface of the anterior leaflet (Fig. 3b). The posterior leaflet had short chordae tendineae; the anterolateral and posteromedial commissures were free. The valve leaflets were irregular and appeared mucoid, oedematous, and thickened.

At necropsy the tricuspid valve (Fig. 4) was also dysplastic and mucoid. The anterior and posterior leaflets were directly attached to the anterior papillary muscle and to the conal muscle; the chordae tendineae were absent.

In view of the unusual ventricular activity seen on the vectorcardiogram, a detailed histological study of the atrioventricular specialised tissue was undertaken using previously described techniques. ${ }^{10}$ The normally located sinus node was haemorrhagic. One of the two arteries (Fig. 5) supplying it was stenotic owing to muscular dysplasia of its walls. At the junctional area the atrioventricular node was displaced to the left in close proximity to the attachment of the anterior muscular mitral leaflet (Figs. 6 and 7); in this area the compact node (Fig. 8) showed traumatic damage caused by a surgical suture. The central fibrous body was hypoplastic. Mahaim type accessory fibres penetrated the central fibrous body and connected the compact atrioventricular node to the left side of the crest of the ventricular septum (Fig. 9). The atrioventricular bundle was short; the left bundle branched off prematurely, and the initial part of the right bundle branch had an intramyocardial course. The membranous septum was rudimentary.

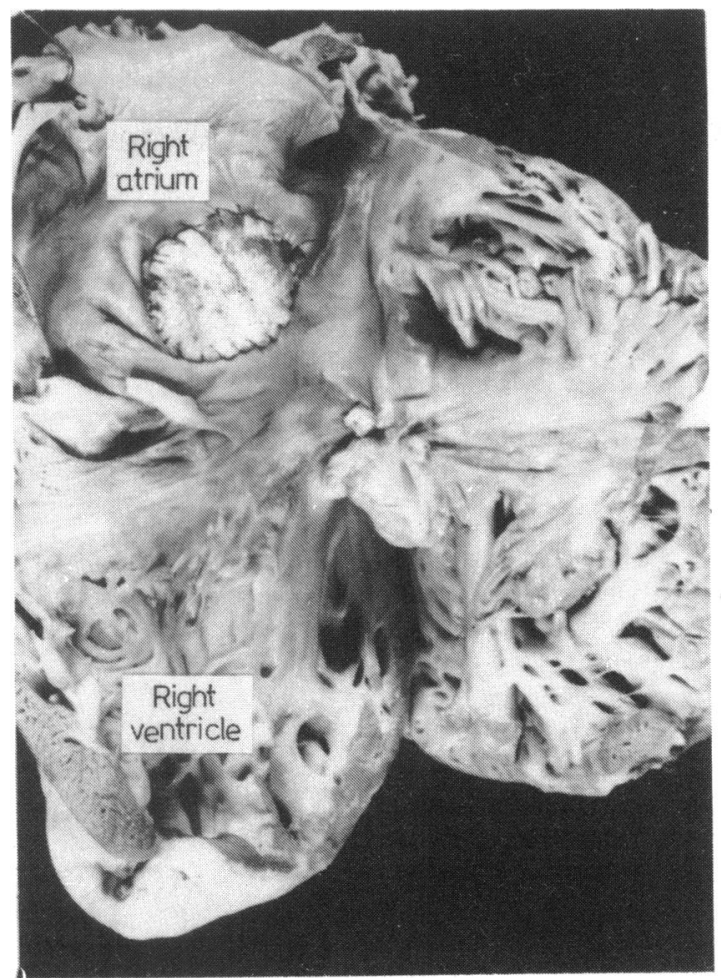

Fig. 4 Macroscopic view of the right sections of the heart (case 1). The tricuspid valve is also dysplastic. The chordae tendineae are absent from the anterior and conal papillary muscles, which are fused with the anterior mucoid leaflet. 


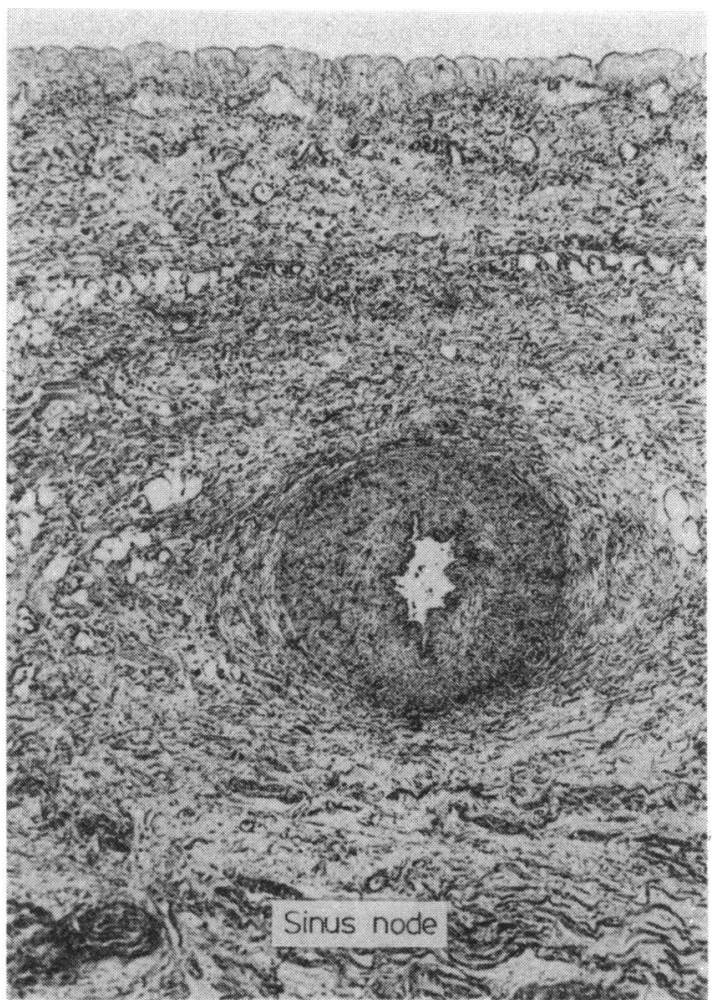

Fig. 5 Case 1: histological section of one of the two arteries supplying the sinus node showing stenosis caused by muscular dysplasia of its walls (case 1). (haematoxylin and eosin $\times 48$ original magnification).

Fig. 6 Case 1: histological section of the posterior region near the coronary sinus. The basal portion of the anterior mitral leaflet is muscular (arrow). (haematoxylin and eosin $\times 6$ original magnification).

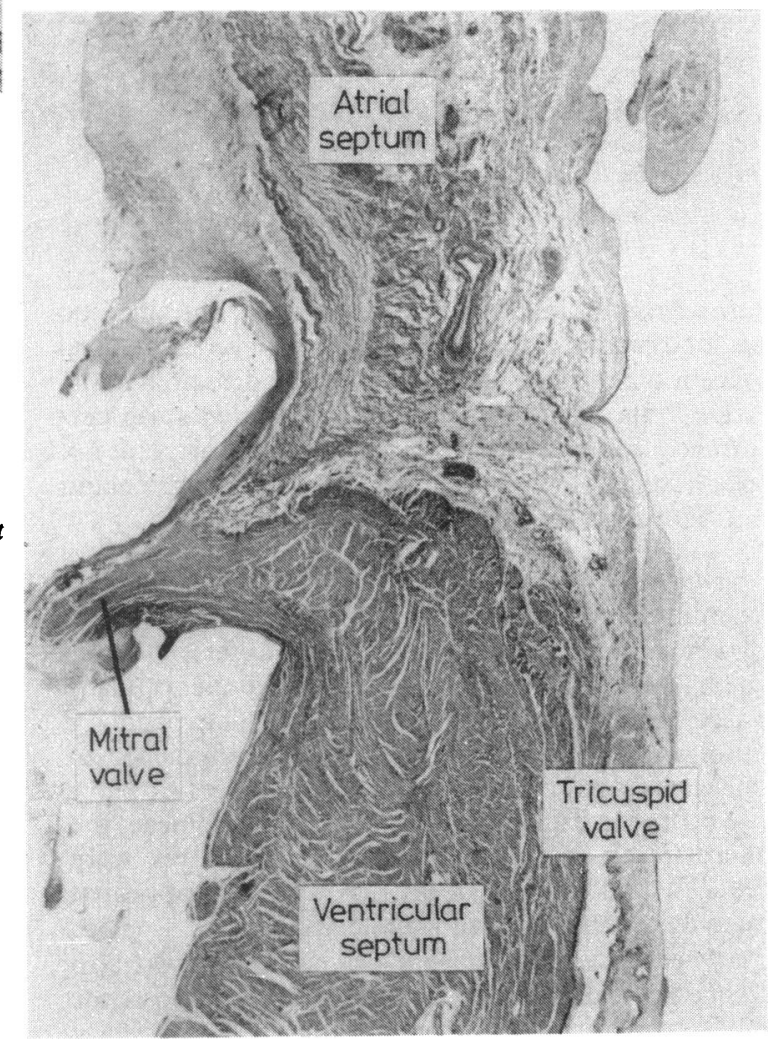



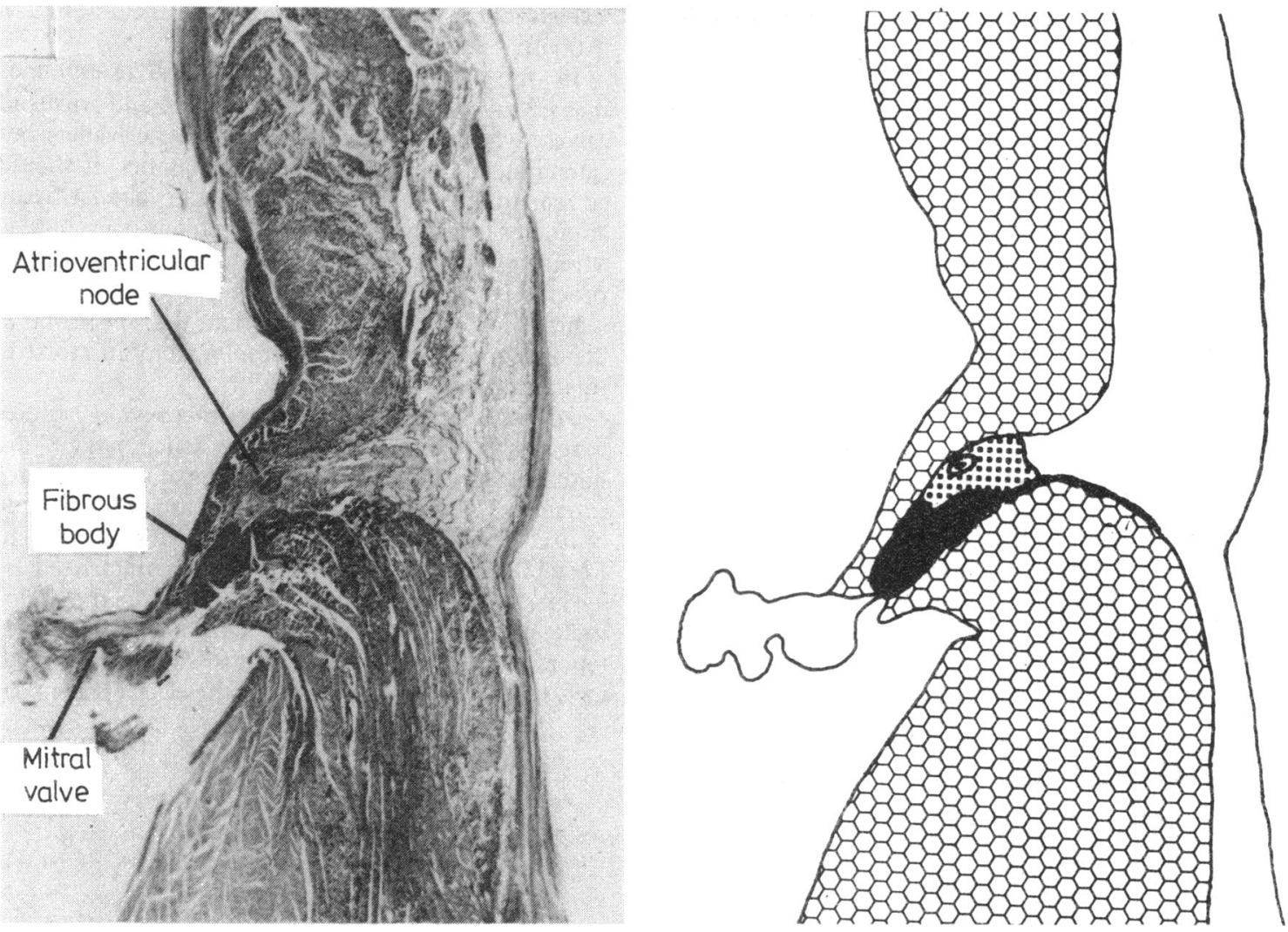

Fig. 7 Case 1: histological section through the atrioventricular node, centred by the atrioventricular nodal artery: note the location on the left side underneath the septal insertion of the anterior mitral leaflet. The central fibrous body is hypoplastic. (Haematoxylin and eosin $\times 5$ original magnification).

CASE 2

The 11 year old sister of case 1 had an atrial septal defect proved at catheterisation performed elsewhere. Her electrocardiogram showed sinus rhythm (75 beats $/ \mathrm{min}, \mathrm{AP}=+35^{\circ}, \mathrm{AQRS}=+110^{\circ}, \dot{\mathrm{AT}}=-35^{\circ}$ ), hypertrophy of the right ventricle, and incomplete right bundle branch block. The vectorcardiogram showed a pattern similar to that of her brother (Fig. 10); clockwise rotation in the frontal, horizontal, and left sagittal planes, and initial QRS forces slightly delayed and directed to the right, posteriorly, superiorly, and downwards, as seen in right bundle branch block, then shifted anteriorly, inferiorly, and to the right.

The phonocardiogram showed an accentuated first heart sound and fixed splitting of the second heart sound, with an increased pulmonary component equal in amplitude to the aortic one. A systolic ejection murmur was recorded in the apical and pulmonary areas, together with a prominent low frequency diastolic rumbling murmur at the apex (Fig. 11a). On an
$M$ mode echocardiogram the moderately thickened anterior mitral leaflet showed a limited diastolic excursion (Fig. 11b).

\section{Discussion}

In previous reports different anatomical conditions have been grouped under the heading "dysplasia of the atrioventricular valves." According to Bharati and Lev ${ }^{11}$ this entity was confined to diffuse or localised proliferation of the spongiosa, vacuolar and lacunar degeneration of the fibrous layer, and a reduction of the elastic components; microscopically the valves appeared to be floppy, with nodular irregular thickening, and the chordae tendineae were often thick and short. These valvular changes, characterised histochemically by an excessive amount of mucopolysaccarides, were found mainly in subjects with chromosomal alterations and in children with the rubella syndrome.

Becker and Edwards' considered "dysplasia" to be 
a condition in which all the valve components-that is, the leaflets, chordae tendineae, and papillary muscles-were malformed, with cusp pathology not confined to the spongiosa but involving any of the three endocardial layers. This definition refers to the tricuspid valve, but it may also be extended to the mitral valve and include the "typical" mitral stenosis described by Ruckman and van Praagh" (characterised by short thick chordae tendineae and reduced interchordal spaces), as well as the "anomalous mitral arcade" of Layman and Edwards ${ }^{3}$ (in which the papillary muscles are in muscular continuity with the anterior mitral leaflet and form an arch). In the same way, structural changes of the valve, such as Ebstein's anomaly and those that are frequently associated with severe obstruction of the right ventricular outflow tract, should also be included in this definition. We accept this meaning for the term dysplasia, according to which the malformation affects different components of the valvular apparatus. In 1968 Hyams and Manion described minor forms of dysplasia of the atrioventricular valves, considering them to be a result of incomplete differentiation of the embryologi- cal structures, ${ }^{12}$ which agrees with the findings of Abbott. ${ }^{13}$

In our patient (case 1) pathological examination showed involvement of both the mitral and tricuspid valves, with dysplasia not limited to the leaflets but extending to the entire valvular apparatus. It should be remembered that while most of the valvular tissue originates from the endocardial cushions, the chordae tendineae and the papillary muscles derive from the progressive delamination of the myocardium. Layman and Edwards maintain that the spectrum of "anomalous mitral arcade" results from an arrest in this process at various stages. ${ }^{3}$

To the best of our knowledge, no previous studies have clarified whether the dysplastic changes are limited to the leaflets and tensor apparatus or if they extend to the surrounding areas, particularly to the central fibrous body and the conduction system. In Ebstein's anomaly, a malformation characterised by dysplasia and abnormal attachment of the valve leaflets, accessory atrioventricular fibres were first reported by Lev et $a l^{14}$ and Sodi-Pallares et $a l^{15}$ and have recently been confirmed by the electrophysiolog-

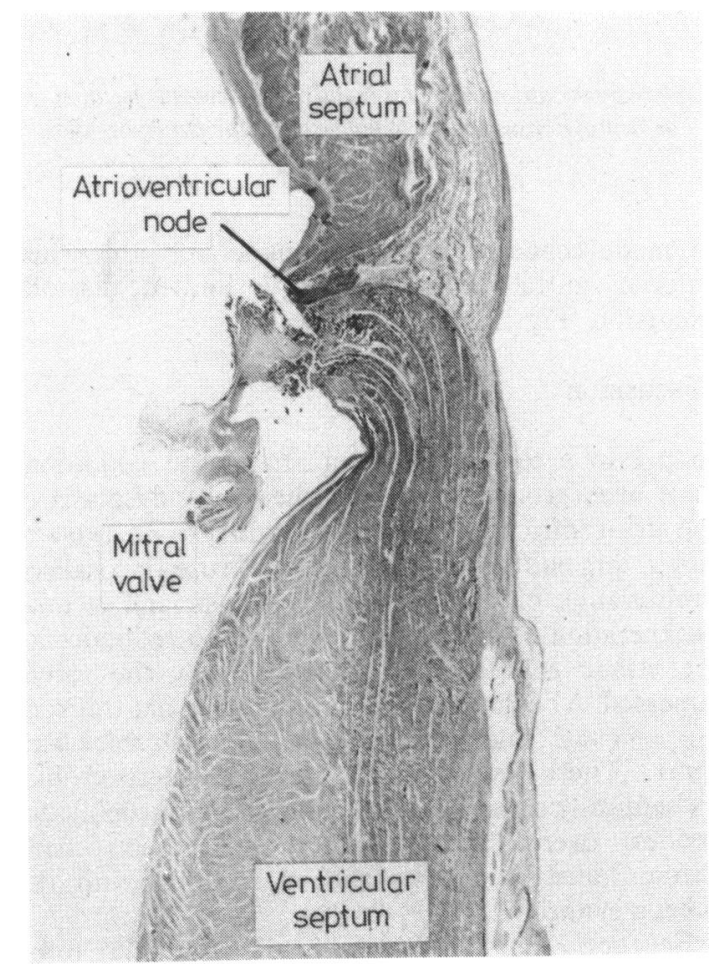

Fig. 8 Case 1: histological panoramic view of the junctional area. A surgical suture has dissected the compact portion of the atrioventricular node. (haematoxylin and eosin $\times 4$ original magnification). 


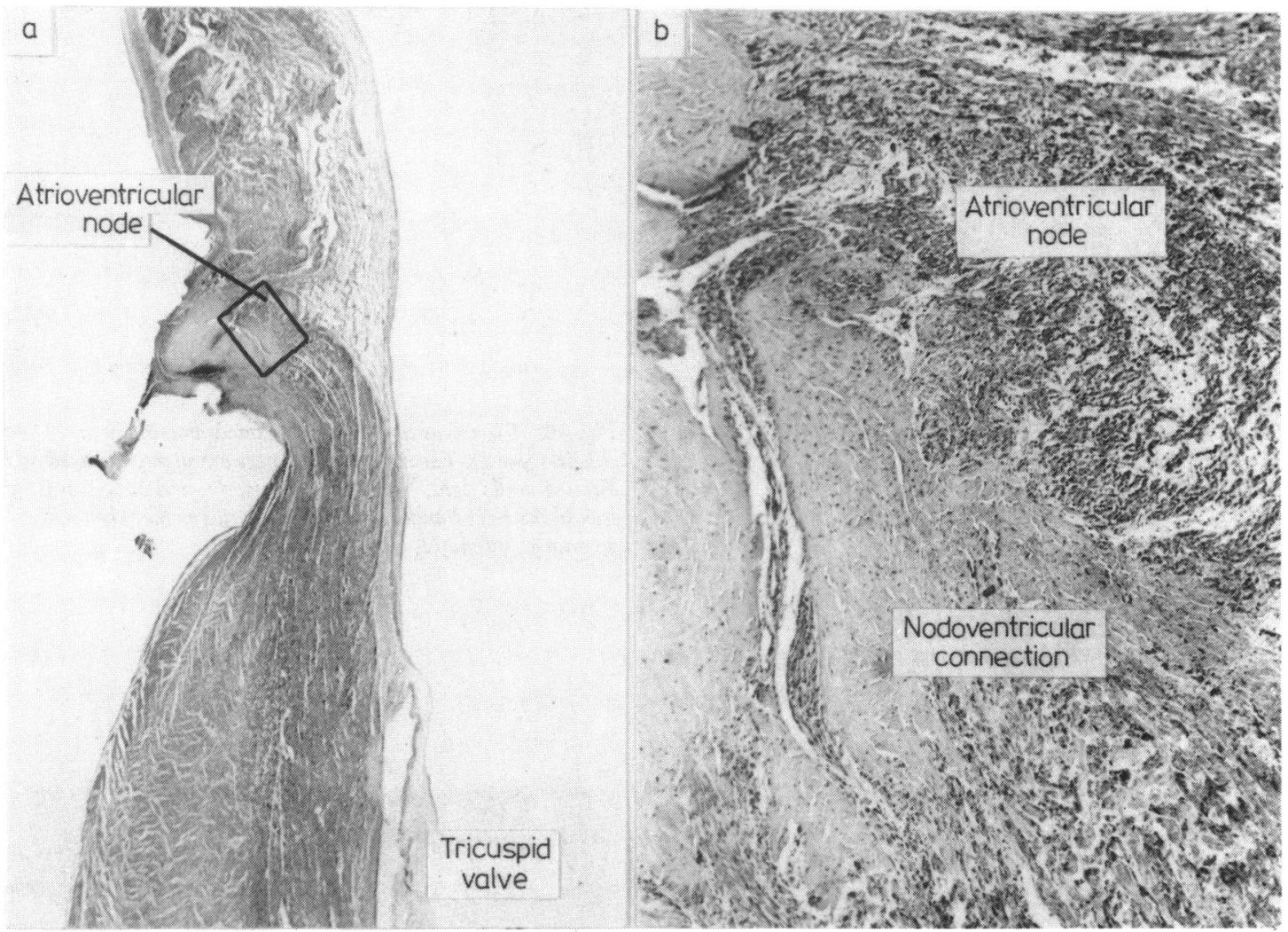

Fig. 9 Case 1: histological panoramic view of the atrioventricular node showing (a) an accessory muscle bundle branching off from the compact node, penetrating the central fibrous body and connecting it to the muscular crest of the interventricular septum, fairly distant from the right side of the ventricular septum; and (b) a detail of the compact atrioventricular node and the nodoventricular accessory connection (in the boxed area of $(a)$ ). Haematoxylin and eosin stain $(a) \times 4 ;(b) \times 25$ original magnification.

ical study of Smith et al ${ }^{16}$ These workers showed that about a third of the patients in their series had multiple accessory pathways which, apart from those cases with an associated corrected transposition, were located on the right. The high incidence of accessory fibres in these patients was due to the presence of centrally or laterally located holes in the fibrous annulus, which favour atrioventricular bypass as a persistence of fetal atrioventricular connexions.

On the basis of our anatomical findings we consider that the process affects other structures of the atrioventricular junction. In our patient the same embryogenetic mistake probably gave rise to the posterior left displacement of the atrioventricular node, as well as to the poor central fibrous body development, the absence of the membranous septum, and the muscular dysplasia of the anterior mitral and tricuspid leaflets. The presence of Mahaim fibres is probably due to the persistence of dispersed conduction tissue, a condition which is typical in the fetal period.
The accessory (Mahaim) pathway is not itself particularly unusual or important, but it is noteworthy when found in conjunction with the other abnormalities.

As a result of the leftward displacement of the atrioventricular node, anomalous Mahaim fibres were located on the left. This possibility is not considered in the classification presented in 1975 by Anderson $e t$ $a l$ at the European Study for Pre-excitation. ${ }^{17}$ Furthermore, the anatomical evidence of nodoseptal fibres explains the unusual ventricular activation seen on the vectorcardiogram in the presence of a normal electrocardiogram; initially, activation proceeded normally, but subsequently the anomalous pathway came into play, thus creating electrical forces that were directed posteriorly, downwards, and to the right. These forces were so great that a complete abnormal loop was recorded.

The clinical and vectocardiogram features seen in the second sibling who did not undergo surgery suggested a similar dysplastic change of the mitral valve 

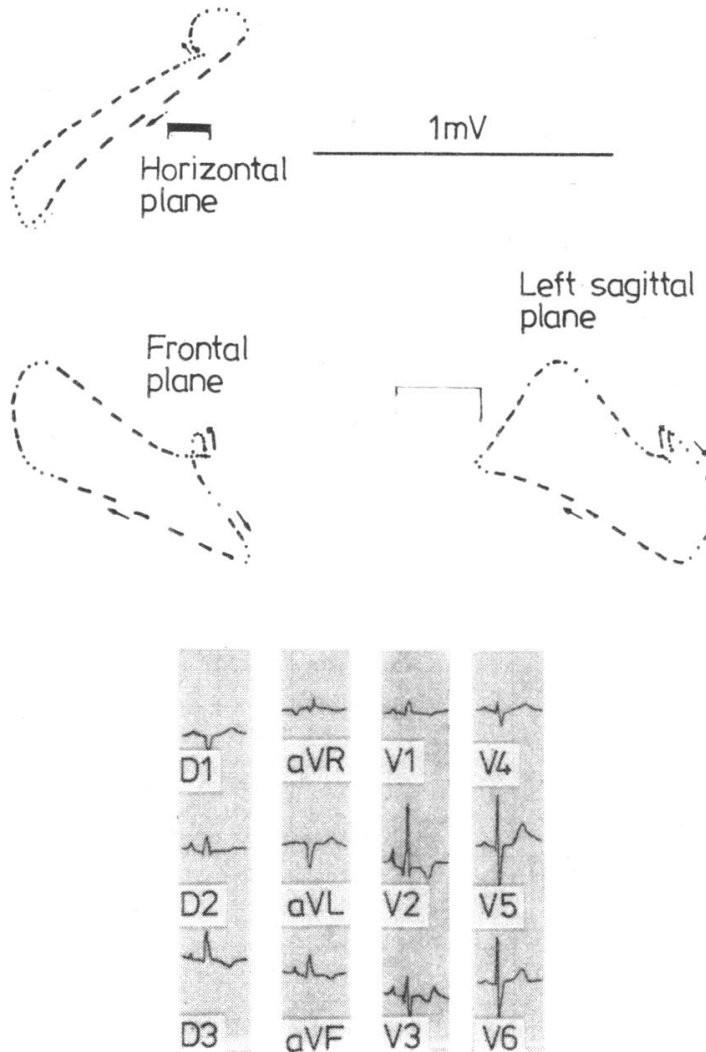

Fig. 11 Case 2: (a) phonocardiogram showing fixed splitting of the second heart sound, an apical systolic murmur (SM) and a prominent low frequency diastolic rumbling murmur (DM) recorded best at the apex; and (b) an $M$ mode echocardiogram showing the anterior mitral leaflet $(A M L)$, mildly thickened, with a low diastolic excursion; the posterior mitral leaflet (PML) is not easily distinguishable from the left ventricular posterior wall echoes. $R V$, right ventricle; $L V$, left ventricle; $L V P W$, left ventricular posterior wall; RVAW, right ventricular anterior wall; IVS, interventricular septum; $A T L$, anterior tricuspid leaflet; $L S B$, left sternal border. 
and anomalous ventricular activation to that seen in the first. A cross sectional echocardiogram is needed to obtain more information about the nature and severity of the atrioventricular valve abnormalities. Because of the analogous findings in the two cases, a leftward displacement of the atrioventricular node in the second sibling is very likely; in view of this possibility the surgeon should beware the risk of damaging the conduction tissue if mitral valve replacement is also required.

The presence of the same anomaly in two siblings supports the hypothesis that the changes described above were not casual but may be classified as a complex malformation syndrome characterised by anomalies of the valvular apparatus, poor development of the central fibrous body and the membranous septum, and abnormal ventricular activation due to atrioventricular node displacement and accessory atrioventricular pathways.

This work has been supported by a grant from the National Research Council (CNR), Rome, and by Opera "Martino Arrigoni", Belluno, Italy.

\section{References}

1 Becker AE, Becker MJ, Edwards MJ. Pathologic spectrum of dysplasia of the tricuspid valve. Arch Pathol Lab Med 1971; 91: 167-78.

2 Ruckman RN, van Praagh R. Anatomic types of congenital mitral stenosis: report of 49 autopsy cases with consideration of diagnosis and surgical implications. Am $\mathcal{F}$ Cardiol 1978; 42: 592-601.

3 Layman TE, Edwards JE. Anomalous mitral arcade: a type of congenital mitral insufficiency. Circulation 1967; 35: 389-95.
4 Antia NV, Osunkoya BO. Congenital tricuspid incompetence. Br Heart f 1969; 31: 664-6.

5 Ariel MB. Ein seltener fall angeborenem Herzfehler bei einem Neu geborenen. Virchows Arch [Pathol Anat] 1930; 277: 501-6.

6 Gallo P, Bastianon V, Colloridi V. Tricuspid valvular dysplasia in the newborn. Appl Pathol (in press).

7 Hozt A. Uber angeborene Trikuspidalinsuffizienz. Fahrbuch Fur Kinderhiel Kunde 1923; 102: 1-12.

8 Jordan JD, Taylor WT. Case of combined congenital tricuspid and mitral insufficiency. Am $\mathcal{F}$ Dis Child 1966; 111: 105-8.

9 Pernot C, Hoeffel JC, Piwnica A, Henry M. A propos d'un cas d'insuffisance tricuspidienne congenitale. Ann Pediatr 1974; 21: 433-42.

10 Thiene G, Nava A, Rossi L. The conduction system in corrected transposition with situs inversus. Eur $\mathcal{F}$ Cardiol 1977; 6: 57-70.

11 Bharati S, Lev M. Congenital polyvalvular disease. Circulation 1973; 47: 575-86.

12 Hyams VJ, Manion WC. Incomplete differentiation of the cardiac valves. A report of 197 cases. Am Heart $\mathcal{f}$ 1968; 76: 173-82.

13 Abbott ME. Atlas of congenital cardiac disease. New York: American Heart Association, 1936.

14 Lev M, Gibson S, Miller RA. Ebstein's disease with Wolff-Parkinson-White syndrome. Am Heart $\mathcal{F} 1955$; 49: $724-41$.

15 Sodi-Pallares D, Acevedo J, Cisneros F, Marsico F, Alvarado A. Sindrome de Wolff-Parkinson-White en la enfermedad de Ebstein. Arch Inst Cardiol Mex 1955; 25: 17-34.

16 Smith WM, Gallagher JJ, Kerr CR, et al. The electrophysiologic basis and management of symptomatic recurrent tachycardia in patients with Ebstein's anomaly of the tricuspid valve. Am $\mathcal{F}$ Cardiol 1982; 49: 1223-33.

17 Anderson RH, Becker AE, Brechenmacher C, Davies MJ, Rossi L. Ventricular pre-excitation. A proposed nomenclature for its substrates. Eur $\mathcal{F}$ Cardiol 1975; 3: 27-36. 